\title{
Design-Attributes Relative Importance Index (DARII) Analysis for Improve Solid Waste Collection Services among Households in Kano Metropolis, North-Western, Nigeria
}

\author{
Hamisu Alhaji Basiru ${ }^{1}$, Mohd Rusli Yacob $^{2}$, Alias Radam ${ }^{3}$, Latifah AbdManaf ${ }^{4}$ \\ 1,2, 4 (Faculty of Enviromental Studies, University Putra Malaysia, 43400 UPM Serdang, Selangor Darul Ehsan, \\ Malaysia). \\ ${ }^{3}$ (Faculty of Economics and Management, Universiti Putra Malaysia, 43400 UPM Serdang, Selangor Darul \\ Ehsan, Malaysia)
}

\begin{abstract}
The issue of solid waste management (SWM) has persisted in most developing countries, like Nigeria. Despite several attempts at local levels to address this, its existence and effects keep on rising in Kano metropolis. This study explores one of the bases in setting priorities for services improvement to choose from among lists of service attributes in choice experiment survey perhaps to minimize the issue of attribute nonattendance. It warrants researchers to know how importance each service attribute is, for the most suitable perceived attributes relative importance. A technique for determining the relative importance of various service attributes to SWM was examined. A Sample of 230 households was determined using Krejcie and Morgan, and questionnaire survey approach was adopted. Data were analyzed using Relative Importance Index. The analysis showed that a relatively simple method using a ranking of multivariate correlation coefficients from high to low might be the most helpful approach for ranking the relative importance attributes. Findings indicated that collection frequency, disposal method, storage facilities, pre-collection and monthly payment were the most appropriate subset of the entire lists which influences waste collection services improvement in Kano Metropolis.

Keywords:-Attribute Non-Attendance, Attribute Relative Importance Index, Choice Experiment, Solid Waste Management.
\end{abstract}

\section{INTRODUCTION}

Solidwaste management (SWM) is one of the most serious environmental problems in Kano metropolis. Its generation is on the increase both in volume and complexity, perhaps, and these have been associated with the population sprawl, urbanization and change in lifestyles of individuals which posed a serious threat to the environmental quality and human life. According to [1], about 1.3 billion tonnes on an estimate of solid waste are collected per year globally, contributing about $5 \%$ emission of greenhouse gas of the organic component of the solid waste decayed. Solid waste generation in the world is expected to increase to about 2.2 billion tones by 2025 significantly. Ineffective waste management which consists of the poor collection system and inefficient disposal method results in both air, water and land pollutions. Which eventually attribute to the contamination of drinking water sources, thus, spreading waterborne diseases and causing infections to the dwellers. As denoted by [2], Nigeria produces about 25 million metric tonnes of solid waste per year, and $0.49 \mathrm{~kg}$ per capita per day. While, in Kano metropolis shows per capita generation of waste ranges from $0.75 \mathrm{~kg} / \mathrm{day}$ in the suburban area, and 1.2 to $1.7 \mathrm{~kg} /$ day in the city and GRA respectively, perhaps due to variations in the socio-economic status of the residential zones.

Kano state has been the most populated state in Nigeria, and one of the industrialized in the country after Lagos has a huge amount of an estimated 3085tones daily of solid waste generated in the Metropolis [3]. SWM in Kano metropolis has a long history. Date back from the colonial era to independence, waste management has been under the control of the local authorities - with Wakilin Tsafta as the councilor in- charge. During that time, there was a decentralized waste management- East, West, and South, North areas of the metropolis. In the mid-1970s to 1990 s, it shifted to several ministries and various special task forces to handle waste management in the municipality. With the beginning of civil rule in 1990 management of solid waste became a fundamental issue for parties' campaign to seek for an election in Kano state. Therefore, it ends in the establishing the present Refuse Management and Sanitation Board (REMASAB) in 2003. 


\section{HOUSEHOLDS' SOLID WASTE MANAGEMENT ISSUES IN KANO REGION}

SWM is a significant issue of concern facing developing and even developed nations of the world, because of its adverse effects on human health and environmental quality [5]. Nigeria is battling with the issue of households' SWM like most developing nations, these challenges, however, ranges from poor collection coverage; inadequate transportation system; indiscriminate dumping of refuse and open burning; insufficient funds and institutional problems, [6]. Hence, these bottlenecks hamper with an efficient and sustainable waste management systems and development.

Similar observation by [7], about $20 \%$ to $50 \%$ of the annual budget of many urban areas spent on SWM, hence, the collection is still low. SWM is poor, and below standard in most developing nations, it is associated with poor waste storage and collection coverage, lack of accurate data on waste management, indiscriminate waste disposal. Ineffective and inefficient waste management significantly contributed to pollutions of air, water and land, and contaminate sources of water [8].

Rapid population growth in Kano region is perceived as one of the problems for the municipal authorities handling municipal solid wastes for providing effective and efficient waste collection services [9]. Population expansion directly affects land use pattern, if this scenario has not been checked it may lead to the advent of illegal structures creating slums within the neighbourhoods and squalor settlements in the metropolis. Hence, it upsets the initial urban plan and eventually hinders effective and efficient waste collection services and bring about the indiscriminate dumping of refuse. Such open illegal dumps gradually accumulate and become a heap of the mountain, releasing unpleasant odour, and serve as a niche for breeding insect and rodent pests. Moreover, illegal open dumps pose a serious threat to human health, environmental quality, and contaminate sources of water through leaching from the dumpsites [10].

According to [3] waste generation and composition is influenced significantly by social behaviour, income, population, season, economic growth, and climate. In Kano metropolis, solid waste consists of heterogeneous compositions and mixed of both bio-degradable and non-biodegradables materials, waste segregation is absent from the source or during collection for final disposals. Also, similar observation by [11, 4] that the magnitude and diversity of solid waste generation and composition is significantly influenced by population expansion, change in consumption styles, industrialization, climate, culture, seasonal variation and economic growth. Solid waste generated per person is lower in developing countries as compared to that of developed countries due to population density, developed nations comparably produce less organic waste than developing countries [12].

\subsection{Household Solid Waste Management}

SWM issue in the metropolis is unsustainable like in most Nigerian cities, and conceivably it could be connected to the incapability of the municipal authorities managing waste effectively. The proliferation of uncollected heaps of refuse is evident almost everywhere posing serious threats to public health and environmental quality, $[4,12,3]$. Despite that trash bins were allocated in some designated points by the municipal authority, along with major streets, yet, waste is usually dumped openly. Thus, about $2 / 3$ of the urban residents in Kano metropolis do not exploit official dump sites due to poor planning and inadequate road network of some areas. However, waste collection.is not frequent even in the planned urban areas [2].

\subsection{Household Waste Collection and Transportation}

A major capital intensive issue in households' SWM services is linked to the collection and transportation of waste materials in phases. Thus, primary and secondary waste collections, waste collection from households to the officially designated dump sites and from these points to the final disposal sites or landfills respectively. Though there are some private service operators (PSP) in waste management sector, mainly operates on demand and collect some charges as fees contrary to the municipal authority that operate freely. PSPs operates on a weekly basis to collect house- to- house wastes in some places, while, in most areas, there is no steadiness in their services for waste collection. Scavengers were noticeable among the informal waste collectors who operate and scavenging for reuse and recyclable materials, however, scavenging in wastes has its related serious health problem to the scavengers [13]. Informal waste collectors and Scavengers often littering a street in searching and sorting for recyclable waste materials from the waste collection containers, which leads to poor sanitation [14].

\subsection{Household Waste Separation and Recycling}

Source separation of waste materials reduces waste quantity from the waste stream and ease recycling, and reduces the total cost of waste disposal. However, this of waste separation among the households from the source of generation, practice is obviously lacking in Kano region, generated wastes are mixed in a single container. Source-separation of waste materials among households before collection is uncommon in Nigeria, 
$[2,12$,$] , contrasting advanced countries where wastes are usually separated and collected in different containers$ of various labels and colours, for example, papers, metals, plastics, etc. are collected separately, [13,14].

Recycling of waste on the other side, for instance, such technologically advanced nations like America, Japan and Germany, because of their level of sophistication in technology are tremendously utilizing their generated waste into recycling, while, there are very few recycling rate and recycling technology in developing countries like Nigeria, perhaps, wastes recycling is both labour and capital intensive, moreover, absent of recycling bins in most urban cities in developing nations prompt residents in disposing their waste without prior source-separation, noticeable also is the fact that re-used materials have low patronage by individuals, as such poor market makes recycling of waste materials futile, [14].

\section{METHODOLOGY}

Identification of design attributes was done via literature review and focus group discussion (FGD) with both regulatory officials and experts in waste management sector. Also, some cross-section of the target population among the households were interviewed. Compilation of the attributes from literature review was confined to the past related valuation studies on SWM improvement. These distinctive sources produced twenty-one (21) related attributes.

Based on interview feedbacks from stakeholders, however, indicated that three attributes from the twenty-one attributes were considered irrelevant. These attributes include changes in collection trucks mix obtained from [15] and [16], and psychological fear and water pollution adopted from [17]. Ensuing conventional technique [18], these three attributes were considered immaterial, and lastly were scrubbed having seventeen attributes. Finally, these attributes were merged into four broad categories. The itemization pattern is presented as in the table below:

Table 1: Design-Attributes Structure for Solid Waste Management Services:

Attributes for SWM Service Improvement

\begin{tabular}{|l|l|l|c|}
\hline \multicolumn{2}{|l|}{ Non-Monetary Attributes } & \multicolumn{2}{l|}{ Monetary Attribute } \\
\hline Pollution Issues & \multicolumn{1}{l|}{ Regulatory Issues } & \multicolumn{1}{l|}{ Service Quality } & Annual Charge \\
\hline Air Pollution & Service Provider Type & Collection Frequency & Monthly Charge \\
\hline Noise pollution & Compost Collection & Schedule & \\
\hline Water Pollution & Containerization & & \\
\hline $\begin{array}{l}\text { Waterways } \\
\text { Evacuation }\end{array}$ & Land use & Pre-Collection Service & \\
\hline Waste Transport & Penalty for Defaulting & $\begin{array}{l}\text { Door-to-Door } \\
\text { collection }\end{array}$ & \\
\hline Disposal Method & Collection Trucks Mix & & \\
\hline Waste Storage & Psychological Fear & & \\
\hline Waste Separation & & & \\
\hline
\end{tabular}

Source: Researcher's Compilation (2015)

The rationale for this analysis is to genuinely confirm that the attributes for the experimental design are obviously the most relevant ones, to address the issue on the occurrence of attribute non-attendance usually, happens when at post-design level respondents hold a low preference for some included attributes in the final experimental level [19]. DARII offers information that guides researchers against neglecting the most important choice-influencing attribute. Thus, both the omission of the most relevant choice-influencing attributes and attribute non-attendance eventually biased estimates [20,21].

The questionnaire has only two segments. The first section elicits for the respondents' demographic profiles. The other segment presents lists of SWM services improvement attributes. Then, respondents were asked to rate them on a scale to determine the most relevant subset, based on the itemization pattern of designattribute in Table 1, which composes both monetary and non-monetary design attributes. A five-point Likertscale is employed in this study; this is in conformity to preceding Relative Importance Index (RII) literature. Thus, five is denoted as the highest response anchor and was dubbed as 'high impact on respondents' satisfaction', where, 1 is denoted as the lowest response anchor and was tagged as 'low impact on respondents' satisfaction'.

In-house face-to-face administration of a structured questionnaire for data collection was employed to the respondents using cluster random sampling. Finally, 230 questionnaires were administered proportionately. The distribution of the sample size across each of the three neighborhoods was obtained through the following formula: 
Where;

$$
\mathrm{ni}=\frac{\mathrm{Ni}}{\mathrm{N}} \mathrm{n}
$$

$\mathrm{n}=$ Total sample selected

$\mathrm{N}=$ Total household population

$\mathrm{ni}=$ Sample size in each neighbourhood

$\mathrm{Ni}=$ Households population in each neighborhood

Table 2: Sample Size Determination

\begin{tabular}{|c|c|c|}
\hline Neighbourhoods & Number of Households & Sample Size Selected \\
\hline Sharada & 198 & $\mathrm{ni}=\frac{198}{550} \times 230=\mathbf{8 3}$ \\
\hline Kawaji & 105 & $\mathrm{ni}=\frac{105}{550} \times 230=\mathbf{4 4}$ \\
\hline Diso & 247 & $\mathrm{ni}=\frac{247}{550} \times 230=\mathbf{1 0 3}$ \\
\hline Total & $\mathbf{5 5 0}$ & $\mathbf{n = 2 3 0}$ \\
\hline
\end{tabular}

Note: The sample size was determined based on Krejcie and Morgan (1970)

Twenty-one (21) key variables which were identified in the literature review in focus group discussion (FGD) feedback were presented to the respondents to solicit their views. On each of these variables, respondents were asked to indicate the extent to which they perceived the relative importance of the variables that influences based on a five-point scale where: 1-very low through 5-very high. In order to empirically ascertain the attributes accounting for their support for improved solid waste management services in Kano metropolis, and to give an understanding as to the extent to which each factor contribute to the improvement of solid waste management services, Relative Importance Index (RII) was used, because it best fits the purpose of this study. According to [22], observed that RII helps in finding the contribution a particular variable makes to the prediction of a criterion variable.

$$
\text { Relative Importance Index }(\mathrm{RII})=\frac{\sum \mathrm{W} * \mathrm{~A}}{\sum \mathrm{A}}
$$

However, it has been noted that the modified version of the RII is statistically more suitable for computing relative importance of variables for their mean values and standard deviations of the individual variables or factors. Because such values would reflect relative relationship or importance among variables of interest to rationalize comparison [23], they suggest the use of the modified version of RII which generates values that are easily compared in relative terms; the formula below was employed in the calculation of the Relative Importance Index (RII), thus;

$$
\text { Modified Relative Importance Index }(\mathrm{MRII})=\frac{\sum \mathrm{W} * \mathrm{~A}}{\sum \mathrm{A} * \mathrm{~N}}(0 \leq \mathrm{MRII} \geq 1)
$$

Where $\mathrm{W}$ is the weight given to each statement by the respondents ranging from 1 to 5 ; $\mathrm{A}$ is the higher response integer (5), and $\mathrm{N}$ is the total number of those surveyed.

The magnitude is weighted by the maximum value $(\mathrm{A})$ of the response category which depends on the rating scale adopted. Thus, the rating index is expected to range between 0 and 1 irrespective of the rating scale. The closer an attribute's score approaches 1 , the higher is its perceived importance about others and vice-visa. Hence, the Likert scale is turned to a continuum as in figure 1 below.

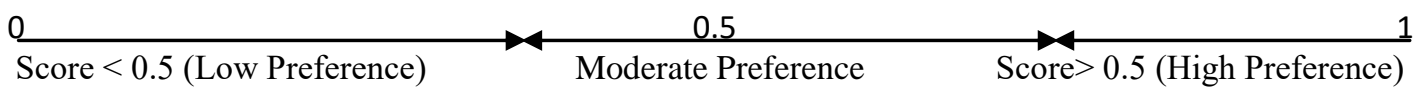

Fig.1: Interpretation of the magnitudes for DARII

Source: Adopted from [24]. 


\section{RESULTS AND DISCUSSIONS}

4.1 Respondents' Profiles

The questionnaire was administered in a face-to-face interview [25], hence, $100 \%$ total responserate was achieved during the data collection. A total of 230 responses were considered for the analysis.

Table3: Households' Socio-economic Profiles

\begin{tabular}{|c|c|c|c|c|c|c|c|}
\hline Variable (s) & Freq. & $\%$ & Mean \pm SD & Min. & Max. & \multicolumn{2}{|c|}{ 95\% Confidence Interval $(\mathrm{Cl})$} \\
\hline & & & & & & $\begin{array}{l}\text { Lower } \\
\text { Bound }\end{array}$ & Upper Bound \\
\hline \multicolumn{8}{|l|}{ Gender } \\
\hline Male & 128 & 55.7 & & & & & \\
\hline Female & 102 & 44.3 & & & & & \\
\hline Age/Age Group & & & 38.11 \pm 13.79 & 18 & 78 & 36.32 & 39.90 \\
\hline Below 30 & 83 & 36.0 & & & & & \\
\hline $31-40$ & 51 & 22.2 & & & & & \\
\hline $41-50$ & 54 & 23.5 & & & & & \\
\hline 51 and Above & 42 & 18.3 & & & & & \\
\hline \multicolumn{8}{|l|}{ Marital Status } \\
\hline Married & 204 & 88.7 & & & & & \\
\hline Single & 12 & 5.2 & & & & & \\
\hline Divorce & 8 & 3.5 & & & & & \\
\hline Widow & 6 & 2.6 & & & & & \\
\hline \multicolumn{8}{|l|}{ Educational Level } \\
\hline Informal education & 9 & 3.9 & & & & & \\
\hline Primary & 2 & 0.9 & & & & & \\
\hline Secondary & 57 & 24.8 & & & & & \\
\hline College/Poly & 85 & 37.0 & & & & & \\
\hline University & 77 & 33.5 & & & & & \\
\hline \multicolumn{8}{|l|}{ Employment } \\
\hline Public & 78 & 33.9 & & & & & \\
\hline Private & 39 & 17.0 & & & & & \\
\hline Self Employed & 58 & 25.2 & & & & & \\
\hline Pensioner & 12 & 5.2 & & & & & \\
\hline Unemployed & 5 & 2.2 & & & & & \\
\hline House Wife & 38 & 16.5 & & & & & \\
\hline Household Size & & & $4.39 \pm 1.67$ & 2 & 9 & 4.17 & 4.60 \\
\hline 2-3 Persons & 70 & 30.4 & & & & & \\
\hline 4-6 Persons & 130 & 56.5 & & & & & \\
\hline 7-9 Persons & 30 & 13.0 & & & & & \\
\hline $\begin{array}{l}\text { Household } \\
\text { Monthly Income }\end{array}$ & & & $58673.91 \pm 42536.73$ & 18000 & 180000 & 53142.42 & 64200.41 \\
\hline N18000-40000 & 104 & 45.2 & & & & & \\
\hline N41000-60000 & 52 & 22.6 & & & & & \\
\hline N61000-80000 & 36 & 15.7 & & & & & \\
\hline N81000 and Above & 38 & 16.5 & & & & & \\
\hline
\end{tabular}

Note: 1 USD $=$ N197 at the time of data collection

The analysis shows that the aggregate age categories of 18 - 40 years (58.3\%) accounts for 134 responses were referred to as the youth/young age groups who constitute the majority of the survey respondents and were within their productive age. With disaggregate of $83(36,1 \%)$ of age category who were below 30 years, another $22.2 \%$ which accounts for 51 respondents out of 230 responses were youth and young age groups respectively. In the second category (31- 40 years), which similarly, shared almost similar characteristics with the first category because the mean sample age was 38.11 which indicates that people that fall within 18-40 years form the bulk of the respondents. The lowest sample age being 18 years and the highest being 78 years old respectively. Statistics also shows that $(23.5 \%)$ were in their middle age, while $(18.1 \%)$ were older age. The age was categorized into four cohorts of $<30,31-40,41-50$ and $>51$ year's age. The cohorts are labelled youth age, young - age, middle-aged and older age groups. 
Also, the statistics show that 204 that constitutes (88.7\%) of the respondents were married while the remaining were either widow, divorced or single. This wide difference within the marital status categories was perhaps due to the recently introduced programme of marrying outs couples by the state government to support, promote and encourage the sustainability of family life in particular among the less privileged ones. Where in 2014 alone the state government married out over 2000 couples and organized and provided their dowries and also empowered them economically, and since then the programme continues up to date annually.

With regards to the educational level, the highest percentage of the respondents (96.2\%) accounts for 221 respondents in aggregate had formal education. With disaggregates of (33.5 \%) university, (37\%) collage/polytechnics, $(24.8 \%)$ secondary and primary only less than $1 \%$, while the remaining $(3.9 \%)$ had no formal education. The majority of the respondents work as public servants $(33.9 \%)$, then the private sector workers who account for $17 \%$, while self-employed accounts for $25.2 \%$ this is expected as Kano been the commercial center of the Northern Nigeria, the remaining (23.9\%) were either unemployed, pensioners or housewives.

The household size or number of members in households of respondents, the variable is employed to describe the number of dependents by each household, and it was categorized into three. Thus, the first categories were those with 2-3 persons who constitute $70(30.4 \%)$, 4-6 persons $130(56.5 \%)$ and 7-9 persons 30 $(13 \%)$ respectively. Thus, the findings reveal that majority of the households have a family size between 4-6 persons which accounts for more $56 \%$, with a sample mean of the household size of about 4.39 , and a maximum of 9 people per household and a minimum of 2 people.

The average monthly gross households' income of the surveyed households was N58, 673.91. With a minimum of $\mathrm{N} 18000$ and maximum of N180000. The majority of households $104(45.2 \%)$ reported a monthly household income extending from N18000 - N40000, (22.6\%) have their monthly income ranging from N41000-N60000, while only $15.7 \%$ and $16.5 \%$ have their monthly earnings ranging from N61000-N80000, as well as N81000 and above respectively.

\section{ATTRIBUTES INFLUENCING SOLID WASTE COLLECTION SERVICES IMPROVEMENT IN KANO METROPOLIS}

Based on survey responses, using a five-point response item, design-attributes relative importance index (DARII) was computed using equation (2). The result in Table 2 ratifies our prior anticipation that all attributes finally employed in this survey from the interview are significant. This is supported by DARII $>0.5$ for all attributes considered based on the rating scale in Figure 1Based on DARII results in Table 2, the pre-design ranking of attributes revealed the top ten (10) important attributes among the seventeen (17) service attributes mentioned above. On the attributes listed in Table 3, landfills reduction (reduction of land designated as disposal facility), waterways evacuation (for free flows drainage system) and time of waste collections (waste collection schedules) are among the ten top but least important in the list. Hence, waste collection frequency, waste storage materials, waste disposal method, monthly collection fees (utility payment for waste collection services) and pre-collection services are top on the list. Thus, DARII could provide information as a guide to a researcher even before experimental design, and it could also minimize the problem of attribute non-attendance in the modelling stage of CE studies [26]. 
Table 4: Design- Attribute Relative Importance Index Determination

\begin{tabular}{|l|c|l|c|c|c|c|c|}
\hline \multicolumn{1}{|c|}{ Category } & I.D & \multicolumn{1}{|c|}{ Attribute Lebel } & $\leq \mathbf{2}$ & $\mathbf{3}$ & $\mathbf{2}$ & DARII & Rank \\
\hline Servce Quality & 1 & Collection Frequency & 0 & 0 & 100 & $\mathbf{0 . 9 8}$ & $\mathbf{1}$ \\
\hline & 2 & Time of Collection & 21.7 & 39.1 & 39.2 & $\mathbf{0 . 6 2}$ & 10 \\
\hline & 3 & Pre-collection Services & 10.4 & 34.3 & 55.2 & $\mathbf{0 . 7 0}$ & $\mathbf{5}$ \\
\hline & & & & & & & \\
\hline Regulatory Issues & 4 & Penalty for Defaulters & 20.9 & 27.8 & 51.3 & $\mathbf{0 . 6 7}$ & 7 \\
\hline & 5 & Landfills Reduction & 14.3 & 50.0 & 35.7 & $\mathbf{0 . 6 5}$ & 8 \\
\hline & 6 & Service Rotation & 51.7 & 24.3 & 23.9 & $\mathbf{0 . 5 1} *$ & 16 \\
\hline & 7 & $\begin{array}{l}\text { Door-to-Door } \\
\text { Collection }\end{array}$ & 15.2 & 37.0 & 48.8 & $\mathbf{0 . 6 8}$ & 6 \\
\hline & 8 & Service Provider & 41.7 & 41.7 & 16.7 & $\mathbf{0 . 5 2}$ & 15 \\
\hline $\begin{array}{l}\text { Pollutions- } \\
\text { Attibutes }\end{array}$ & 9 & Air Pollution & 30.4 & 35.2 & 34.3 & $\mathbf{0 . 6 1} *$ & 12 \\
\hline & 10 & Noise Pollution & 45.2 & 37.4 & 17.4 & $\mathbf{0 . 5 1} *$ & 17 \\
\hline & 11 & Storing Materials & 1.7 & 3.5 & 94.8 & $\mathbf{0 . 9 2} *$ & $\mathbf{2}$ \\
\hline & 12 & Waterways & 21.7 & 40.9 & 37.4 & $\mathbf{0 . 6 3}$ & 9 \\
\hline & 13 & Evacuation & 22.2 & 49.6 & 28.3 & $\mathbf{0 . 6 1} *$ & 11 \\
\hline & 14 & Disposal Method & 1.3 & 3.5 & 95 & $\mathbf{0 . 9 2} *$ & $\mathbf{3}$ \\
\hline & 15 & Containerazation & 38.7 & 24.8 & 36.6 & $\mathbf{0 . 5 8}$ & 13 \\
\hline & 16 & Compost Collection & 40.4 & 23.5 & 36.1 & $\mathbf{0 . 5 7}$ & 14 \\
\hline & & & & & & & \\
\hline & & & 1.3 & 6.5 & 92.1 & $\mathbf{0 . 7 2}$ & $\mathbf{4}$ \\
\hline
\end{tabular}

*Attributes with equal magnitude of RII are ranked according to the percentage scoring 4 or above of respondents.

\section{CONCLUSION}

This paper has examined design-attribute relative importance index (DARII) based on the respondents' self-reported choice-influencing attributes for households' solid waste collection services improvement. The result confirms our prior expectation based on the interview outcome that only most important service influencing attributes will be included in the model. This was demonstrated by DARII values greater than 0.5 for all attributes. Thus, waste collection frequency, waste storage materials, waste disposal method, monthly charges for waste collection services and pre-collection services were utmost important service attributes of solid waste collection services favored among households in Kano metropolis. This has policy implications to the relevant stakeholders, for both the policy makers and private firms in solid waste management sector. This findings provide an understanding into the factors that contribute to the waste collection services improvement desired by households.

\section{REFERRENCES}

[1] Hoornweg, D., and Bhada-Tata, P,What a waste: a global review of solid waste management, Available at https//openknowledge.worldbank.org/handle/10986/17388. Accessed on $25^{\text {th }}$ December, 2015.

[2] Nabegu, A. B., and Wudil, P, An assessment of Refuse Management and Sanitation Board (REMASAB) Solid waste management in Kano metropolis, Techno-Science Africana Journal, 1, 2008, 101-108.

[3] Nabegu, A. B, An analysis of municipal solid waste in Kano metropolis, Nigeria. Journal of Human Ecology, 31(2), 2010, 111-119.

[4] Medina, M, Globalization, development, and municipal solid waste management in third world cities. Institute of Advance Studies, Mexico, 2002, 1-23.

[5] Aliu, I. R., Adeyemi, O. E., and Adebayo, A, Municipal household solid waste collection strategies in an African megacity: analysis of public private partnership performance in Lagos. Waste Management \& Research, 32(9), 2014, 67-78.

[6] Imam, A., Mohammed, B., Wilson, D. C., and Cheeseman, C. R, Solid waste management in Abuja, Nigeria. Waste management, 28(2), 2008, 468-472. 
[7] Achankeng, E,Globalization, urbanization and municipal solid waste management in Africa. In Proceedings of the African Studies Association of Australasia and the Pacific, (2003), 26th Annual Conference.

[8] UNICEF, W, WHO Joint Monitoring Programme for Water Supply and Sanitation. Progress on drinking water and sanitation, 2012.

[9] Olanrewaju, O. O., and Ilemobade, A. A, Waste to wealth: A case study of the Ondo State integrated wastes recycling and treatment project, Nigeria. European Journal of Social Sciences, 8(1), 2009, 7-16.

[10] Karunakaran, K., Thamilarasu, P., and Sharmila, R, Statistical study on physicochemical characteristics of groundwater in and around Namakkal, Tamilnadu, India. Journal of Chemistry, 6(3), 2009, 909-914.

[11] Lau, V. L. (2004). Case study on the management of waste materials in Malaysia. In Forum Geookol (Vol. 15, No. 2, pp. 7-14)

[12] Ogwueleka, T, Municipal solid waste characteristics and management in Nigeria. Journal of Environmental Health Science \& Engineering, 6(3), 2009, 173-180.

[13] Chung, S. S., and Poon, C. S, A comparison of waste-reduction practices and new environmental paradigm of rural and urban Chinese citizens. Journal of Environmental Management, 62(1), 2001, 3-19.

[14] Hui, Y., Li'ao, W., Fenwei, S., and Gang, H, Urban solid waste management in Chongqing: Challenges and opportunities. Waste management, 26(9), 2006, 1052-1062

[15] Afroz, R., and Masud, M. M, Using a contingent valuation approach for improved solid waste management facility: Evidence from Kuala Lumpur, Malaysia. Waste management, 31(4), 2011, 800808.

[16] Afroz, R., Hanaki, K., and Hasegawa-Kurisu, K, Willingness to pay for waste management improvement in Dhaka city, Bangladesh. Journal of environmental management, 90(1), 2009, 492-503.

[17] Pek, C. K., and Jamal, O, A choice experiment analysis for solid waste disposal option: A case study in Malaysia. Journal of environmental management, 92(11), 2011, 2993-3001.

[18] Hanley, N., Wright, R. E., and Adamowicz, V, Using choice experiments to value the environment. Environmental and resource economics, 11(3-4), 1998, 413-428

[19] Hess, S., and Hensher, D. A, Making use of respondent reported processing information to understand attribute importance: a latent variable scaling approach. Transportation, 40(2), 2013, 397-412.

[20] Hess, S, Impact of unimportant attributes in stated choice surveys. European Journal of Transport and Infrastructure Research, 14(4), 2014, 349-361.

[21] Alemu, M. H., Mørkbak, M. R., Olsen, S. B., and Jensen, C. L, Attending to the reasons for attribute nonattendance in choice experiments. Environmental and resource economics, 54(3), 2013, 333-359.

[22] Johnson, J. W., and LeBreton, J. M, History and use of relative importance indices in organizational research. Organizational Research Methods, 7(3), 2004, 238-257.

[23] Bari, N. A. A., Yusuff, R., Ismail, N., Jaapar, A., and Ahmad, R, Factors influencing the construction cost of industrialised building system (IBS) projects. Procedia-Social and Behavioral Sciences, 35, 2012, 689696.

[24] Kometa, S. T., Olomolaiye, P. O., and Harris, F. C, Attributes of UK construction clients influencing project consultants' performance. Construction Management and Economics, 12(5), 1994, 433-443.

[25] Bateman, I. J., Carson, R. T., Day, B., Hanemann, M., Hanley, N., Hett, T., and Loomes, G, economic valuation with stated preference techniques (Cheltenham: Edward Elgar, 2002).

[26] Adam, S. U., Shamsudin, M. N., Sidique, S. F., Rahim, K. A., and Radam, A, Attribute prioritization in choice experiment pre-design: suggested method and application to solid waste management service improvement. Journal of Energy Technologies and Policy, 3(11), 2013, 291-298. 